\title{
There are still problems in identifying who will develop complications of sore throat in primary care
}

\author{
Jan Matthys general practitioner, lecturer in general practice
}

University of Ghent, University Hospital, 1K6, 9000 Ghent, Belgium

In Little and colleagues' study of the predictors of suppurative complications for acute sore throat in primary care, "complicated illness" was an exclusion criterion. ${ }^{1}$ Indeed, in guidelines from the Netherlands and Belgium, ${ }^{2}$ antibiotics are recommended only in very ill and high risk patients (immunocompromised), who comprise about $5 \%$ of patients with sore throat in general practice. I assume that this is what the authors meant by "complicated illness" or "safety netting."

Little and colleagues suggest that inflammatory markers such as $\mathrm{C}$ reactive protein might help predict suppurative complication but not all studies agree.

To control possible complications or to manage uncertainty, the authors and the linked editorial suggest a "delayed prescription" strategy. However, a Cochrane review indicated that such a strategy reduced antibiotic use compared with immediate antibiotic prescribing in respiratory infections, but that most studies found that complication rates were no different from those seen with a "no antibiotics" prescribing strategy. ${ }^{3}$

I agree with the authors and editorial that doctors overestimate patients' expectations of an antibiotic prescription. A Belgian study found that most people with sore throat visit their doctor for reassurance and pain relief-hopes of an antibiotic ranked only 11 th of 13 items. ${ }^{4}$ And another study found a reduction in new antibiotic prescriptions when patients had the opportunity to express their expectations (reassurance, pain relief) or concerns. ${ }^{5}$

Unfortunately, history, scores, examination, and tests cannot identify those who will develop complications, as Little and colleagues seem to conclude. Perhaps further research into antibiotic prescribing strategies should focus on identifying patient groups at high risk of complications, ${ }^{3}$ enhancing doctors' communication with patients to maintain satisfaction, and investigating how to reduce doctors' anxieties about not prescribing antibiotics for sore throat. ${ }^{35}$

Competing interests: None declared.

1 Little P, Stuart B, Hobbs FDR, Butler CC, Hay AD, Campbell $J$, et al; on behalf of the DESCARTE investigators. Predictors of suppurative complications for acute sore throat in primary care: prospective clinical cohort study. BMJ 2013;347:f6867. (25 November.) 2 Matthys J, De Meyere M, van Driel ML, De Sutter A. Differences among International pharyngitis guidelines: not just academic. Ann Fam Med 2007;5:436-43.

3 Spurling GK, Del Mar CB, Dooley L, Foxlee R. Delayed antibiotics for respiratory infections. Cochrane Database Syst Rev 2007;3:CD004417.

4 Van Driel ML, De Sutter A, Deveugele M, Peersman W, Butler CC, De Meyere M, et al. Are sore throat patients who hope for antibiotics actually asking for pain relief? Ann Fam Med 2006;4:494-9.

5 Matthys J, Elwyn G, Van Nuland M, Van Maele G, De Sutter A, De Meyere M, et al. Patients' ideas, concerns, and expectations (ICE) in general practice: impact on prescribing Br J Gen Pract 2009;59:29-36.

Cite this as: $B M J$ 2014;348:9299

๑ B BMJ Publishing Group Ltd 2014 